This is a post-print version of the following article:

Chen, J., Halappanavar, S.S., St-Germain, J.G., Tsang, B.K. \& Li, Q. (2004). Role of Akt/protein kinase B in the activity of transcriptional coactivator p300. Cellular and Molecular Life Sciences 61(13), 16751683. doi: 10.1007/s00018-004-4103-9

\title{
Role of Akt/protein kinase B in the activity of transcriptional coactivator p300
}

J. Chen ${ }^{1}$, S.S. Halappanavar ${ }^{1}$, J.G. St-Germain ${ }^{1}$, B.K. Tsang ${ }^{1,3,4}$ and Q. Li ${ }^{1,2,3^{*}}$

${ }^{1}$ Ottawa Health Research Institute, Departments of ${ }^{2}$ Cellular \& Molecular Medicine,

${ }^{3}$ Medicine, and ${ }^{4}$ Obstetrics \& Gynecology, University of Ottawa, 725 Parkdale Ave, Ottawa, Ontario, K1Y 4E9, Canada

"Corresponding author: The Ottawa Health Research Institute 725 Parkdale Ave.

Ottawa, Ontario, Canada, K1Y 4E9

Phone: (613) 798.5555, ext.13454

Fax: (613) 7615036

Email: qli@ohri.ca

Running title: Regulation of p300 by Akt. 


\begin{abstract}
Akt/protein kinase B is a downstream target of PI3K pathway and plays a critical role in promotion of cell survival. The function of transcriptional coactivator $\mathrm{p} 300$ is required by many transcription factors to either activate or repress gene expression. Here, we show that induction of PI3K enhances the metabolic stability of endogenous p300 protein. On the other hand, repression of PI3K by LY294002 induces p300 degradation through the $26 \mathrm{~S}$ proteasome pathway and impedes the transcriptional activity of the coactivator. In addition, Akt interacts with the coactivator and the activity of Akt is required for maintaining the steady-state level of p300. Our study provides a new insight into the molecular mechanisms by which the critical concentration of $\mathrm{p} 300$ protein is regulated and suggests a role for Akt in control of various cellular activities through the transcriptional coactivator $\mathrm{p} 300$.
\end{abstract}

Key words: Akt, protein kinase B, PI3K, p300, coactivator, protein degradation, proteasome, cellular signaling. 


\section{Introduction}

Transcriptional coactivator $\mathrm{p} 300$, a histone acetyltransferase, acts in concert with many DNA binding proteins to facilitate signal-modulated chromatin remodeling and gene expression that control an array of cellular functions, including proliferation and differentiation [1]. Mice lacking both p300 alleles exhibit specific transcriptional defects, poor proliferation and die around midgestation. Interestingly, mice heterozygous for p300 also exhibit retarded growth, heart and brain abnormalities and significant embryonic lethality, underlying the importance of tight regulation of the steady-state level of p300 and its activity during proliferation, development and growth [2].

Many lines of evidences have demonstrated p300 as a transcriptional integrator of multiple signaling pathways [3-5]. However, very little is known about how the activity of p300 itself is regulated in response to internal and external stimuli. Some studies suggest that post-translational modifications, such as phosphorylation and ubiquitination, may play a role in modulating the transcriptional activity of p300 [6-11]. Recently, Girdwood et al. demonstrated that p300 is modified by ubiquitin-like protein SUMO, and this modification leads to transcriptional repression of p300, suggesting yet another mechanism for controlling the transcriptional activity of p300 [12].

The discoveries of histone deacetylase inhibitors, such as sodium butyrate, have provided powerful tools to study acetylation and transcription. While histone deacetylase inhibitors, generally, enhance gene expression from various promoters $[4,5,13,14]$, sodium butyrate inhibits the activation of the tyrosine aminotransferase gene and MMTV promoter [15-18] through stimulating selective p300 degradation [9]. In addition, sodium butyrate and other histone deacetylase inhibitors affect a variety of cellular processes, 
such as cell growth, differentiation and apoptosis by mechanisms that are still unknown [19-22].

Akt, also known as protein kinase $\mathrm{B}(\mathrm{PKB})$, is a downstream effector of PI3K and has been implicated in several cellular processes including proliferation, growth and metabolism [23]. Three members of the Akt/ PKB family have been identified in mammalian cells: Akt1/ PKB $\alpha, \mathrm{Akt} 2 / \mathrm{PKB} \beta$ and Akt3/PKB $\gamma$, which, in general, are widely expressed $[23,24]$. They are activated by a variety of stimuli, such as hormones, growth factors and cytokines in a PI3K-dependent manner [25]. A growing body of evidence suggests that Akt has an essential role in promoting cell survival. Dominant negative mutants of Akt reduce the rates of cell survival in granule cells, whereas overexpression of wild-type or constitutively active Akt enhances the rate of cell survival in the absence of growth factors [26]. The ability of constitutively active Akt to inhibit apoptosis induced by UV irradiation, matrix detachment and DNA damage has also been observed in a variety of cell types [27-30].

Molecular mechanisms by which Akt promotes cell survival depends on multiple factors. The function of Akt is mediated through phosphorylation of substrate proteins and the consensus sequence optimal for Akt phosphorylation has been established as RXRXXS/T [31, 32]. Transcriptional coactivator $\mathrm{p} 300$ is one of the potential substrates subject to Akt phosphorylation $[33,34]$. Studies of the downstream targets of Akt suggest that Akt phosphorylation inhibits directly or indirectly the activity of many proapoptotic factors, such as BAD, caspase 9, transcription factors of the forkhead family and p53 [35-39]. Apart from being a negative regulator of apoptosis, Akt also promotes cell survival by down-regulating the inhibitor of pro-survival pathways. For example, 
phosphorylation of IкB-kinase (IKK) by Akt induces the proteasome-mediated

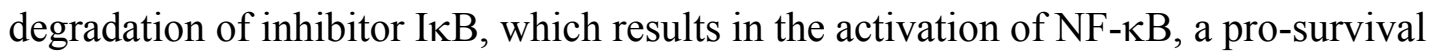
transcription factor [40-42].

Here, we identify Akt as a positive regulator of p300, whose integrator activity is required for proliferation and growth during development. We show that Akt interacts with the transcriptional integrator $\mathrm{p} 300$ and Akt activity is required for sustaining the steady-state level of endogenous p300 protein. 


\section{Material and Methods}

Plasmids and reagents. The expression plasmids for GST-p300 fusion proteins, constitutive active Akt and $\beta$ RE3-Luc reporter have been described previously [43-45]. MG132 was purchased from Sigma. LY294002, MG115, MG101 and lactacystin were from Calbiochem. Antibodies against p300, RAR $\beta$, cyclin E, SRC and p53 were acquired from Santa Cruz and antibodies specific for Akt and phospho-Akt were from Cell Signaling.

Cell culture and transfection. Tissue culture cells were maintained in modified Eagle's medium (DMEM) supplemented with 10\% fetal bovine serum (FBS, Hyclone) and were cultured for a minimum of 16 hours prior to various treatments. Transient transfections were performed with ExGen 500 using the amount of plasmid DNA indicated in the legends [9]. After transfection, the cells were cultured in DMEM supplemented with 10\% FBS for 24 hours, then treated with LY294002 $(20 \mu \mathrm{M})$ and/or TTNPB $(1 \mu \mathrm{M})$ for indicated hours. Luciferase assay was performed according to the manufacturer's recommendation (Promega). Luciferase activity was expressed as fold induction (normalized to $\beta$-Gal activity) relative to untreated controls. The experiment was repeated three times in triplicate.

Whole cell extracts and immunoprecipitation. For the preparation of whole-cell extracts, cells were incubated with buffer W containing $50 \mathrm{mM}$ Tris- $\mathrm{HCl}(\mathrm{pH}$ 7.6), 400 $\mathrm{mM} \mathrm{NaCl}, 10 \%$ glycerol, $0.5 \mathrm{mM}$ DTT, $0.5 \mathrm{mM}$ PMSF and $1 \% \mathrm{NP}-40$ at $4^{\circ} \mathrm{C}$ for 30 
minutes. Lysate was purified by centrifugation at $14,000 \mathrm{x}$ g at $4{ }^{\circ} \mathrm{C}$ for 10 minutes. Protein concentration was determined using the Bradford assay (Bio-Rad) with bovine serum albumin as standard. For the immunoprecipitation procedure, the $\mathrm{NaCl}$ concentration of whole-cell extracts was adjusted to $150 \mathrm{mM}$ and the NP-40 concentration to $0.1 \%$. Extracts were incubated with protein $\mathrm{A}$ and the indicated antibodies at $4^{\circ} \mathrm{C}$ for 2 hours. All experiments were carried out at least three times.

Metabolic labeling. Cells were cultured in DMEM supplemented with 10\% FBS for 22 hours. The media was then replaced with methionine-free media and the cells were further cultured for an additional 2 hours with $100 \mu \mathrm{Ci} / \mathrm{ml}$ of ${ }^{35} \mathrm{~S}$-methionine and harvested for the preparation of whole-cell extracts. The incorporated radioactivity was measured by scintillation counting of the whole-cell extracts and the rate of protein synthesis was calculated as the measured radioactivity per microgram of protein. The half-life of p300 was determined by the remaining incorporated radioactivity of immonoprecipitated p300 following various hours of chase. The quantification was performed using a PhosphoImager (Molecular Dynamics).

Flow Cytometry Analysis. Following various treatments, cells were harvested and fixed overnight at $-20^{\circ} \mathrm{C}$ in $70 \%$ ethanol. They were then treated with $50 \mu \mathrm{g} / \mathrm{ml}$ RNase A and stained with $50 \mu \mathrm{g} / \mathrm{ml}$ of propidium iodide at $37^{\circ} \mathrm{C}$ for 30 minutes. DNA contents of the cells were analyzed by fluorescence activated cell sorter (Becton and Dickinson) to determine the distribution of cells in different phases of the cell cycle. 
Immunofluorescence microscopy. Cells were grown on glass coverslips for about 14 hours before treatment. The cells were then fixed in 4\% paraformaldehyde, permeabilized in $0.2 \% \mathrm{NP}-40$ and blocked in PBS containing $0.2 \%$ tween 20 and $10 \%$ non-fat milk [46]. The coverslips were incubated with primary antibody specific for p300 (1:300, Santa Cruz) or Akt (1:200, Cell Signaling), then with rhodamine-conjugated secondary antibody (1:150, Jacksons), mounted in 90\% glycerol and visualized by fluorescence microscopy.

Quantitative RT-PCR. Total RNA from cells was isolated using the RNeasy Mini Kit (Qiagen) and $0.5-1 \mu \mathrm{g}$ of the total RNA was reverse transcribed with 200 units of Superscript II (Invitrogen) at $42^{\circ} \mathrm{C}$ for 50 minutes as recommended (Invitrogen). Quantitative PCR was performed with $1 \mu \mathrm{l}$ of the resulting cDNA using 2.5 units of Platinum Taq DNA Polymerase (Invitrogen), and p300 primers which amplified the 2931-3037 region of p300 mRNA, resulting in a 130-bp PCR product. To account for cell number variations and RT-PCR variables, 18S RNA Internal Standard (Ambion) was used in the PCR reactions which were amplified in duplicate for 20-30 cycles. The PCR products were then resolved on a $1.5 \%$ agarose gel, stained with Vistra Green (Amersham), detected with the Typhoon 8600 Variable Mode Imager (Molecular Dynamics) and quantified using ImageQuant software (Molecular Dynamics). The ratios of p300 and 18S from treated cells were calculated and compared to that from untreated cells. 


\section{Results}

\section{Cycloheximide does not reduce the steady-state level of endogenous p300.}

Sodium butyrate, a histone deacetylase inhibitor [47], has previously been reported to reduce the abundance of endogenous p300 protein and inhibit steroid-induced transcription that depends on the function of transcriptional coactivator p300 [9]. The negative effect of sodium butyrate on the abundance of p300 protein may be a secondary result of the expression of certain genes, since treatment of cells with histone deacetylase inhibitor renders chromatin structure more accessible for transcriptional activation [48]. To determine whether the down-regulation of $\mathrm{p} 300$ protein by sodium butyrate requires de novo protein synthesis, we examined the abundance of endogenous p300 protein upon sodium butyrate treatment in the presence of cycloheximide. As shown in figure 1A, treatment of HeLa cells with cycloheximide, a ribotoxin that inhibits ribosome translocation [49], attenuated the reduction of $\mathrm{p} 300$ protein induced by sodium butyrate. However, the level of endogenous p300 protein was still very abundant even after 24 hours of treatment with cycloheximide (Fig. 1A). This was quite surprising, as previous studies have shown that the half-life of endogenous p300 protein is in the range of 9-14 hours, depending on the methodology and cell lines employed $[10,50]$. We thus conducted several control experiments to verify the efficacy of cycloheximide.

First, we examined the abundance of cyclin E protein in response to cycloheximide treatment with the same protocol. Western analysis showed that the levels of cyclin E protein were significantly reduced upon the cycloheximide treatment (Fig. 1B). Second, the efficacy of cycloheximide was confirmed by metabolic labeling procedure. As shown in Fig. 1C, general protein synthesis was effectively blocked to 
about $15 \%$ of controls in the cycloheximide-treated cells. Third, using a pulse-chase protocol, we determined that the apparent half-life of p300 protein in the HeLa cells is about 11 hours in the absence of cycloheximide, which is in agreement with previous studies (Fig. 1 D). In addition, as with cycloheximide, treatment of the cells with anisomycin, a ribotoxin that blocks peptidyl transfer [51], did not significantly reduce much the abundance of $\mathrm{p} 300$ protein (data not shown).

Taken together, these results indicate that cycloheximide, while inhibits de novo protein synthesis in general, maintains the steady-state level of endogenous p300 possibly through increasing the protein stability of the coactivator. Cycloheximide has been reported to trigger cellular stress and activate the PI3K pathway [52]. We hence wish to explore a possible role of PI3K pathway in maintaining the activity of transcriptional coactivator p300.

\section{LY294002 stimulates p300 degradation through the 26S proteasome pathway.}

To study the potential role of PI3K in the regulation of metabolic stability of endogenous p300, we employed a selective PI3K inhibitor, LY294002 [53]. As shown in

Fig. 2A, the steady-state level of endogenous p300 protein in HeLa cells was reduced significantly following the administration of LY294002 to the culture, and cotreatment of the cells with cycloheximide counteracted negative effects of LY294002 on the abundance of $\mathrm{p} 300$ protein (Fig. 2A). In addition, treatment of the cells with wortmannin, another specific PI3K inhibitor [54] likewise resulted in the reduction of the endogenous $\mathrm{p} 300$ protein (data not shown). 
Most interestingly, MG132, a peptide aldehydes that reversibly inhibits the $26 \mathrm{~S}$ proteasome activity [55], prevented the down-regulation of $\mathrm{p} 300$ protein by LY294002, implying that the 26S proteasome pathway may be involved in the LY294002-stimulated p300 degradation. To verify the specific activity of the $26 \mathrm{~S}$ proteasome in the LY294002-induced p300 down-regulation, we also used the most specific proteasome inhibitor, lactacystin, since MG132 can also impede certain lysosomal cysteine proteases and calpain [55]. Western analysis demonstrated that treatment of cells with lactacystin inhibited the LY294002-stimulated p300 degradation, as elicited by MG132 (Fig. 2B). Furthermore, like MG132, other proteasome inhibitors, such as MG115 and MG101 [55], all counterbalanced the negative effect of LY294002 on the steady-state level of endogenous p300 protein (Fig. 2C). Immunofluorescence microscopy analysis revealed that the p300 stain was reduced upon treatment with LY294002 but not upon that with MG132 (Fig. 2D). Cell cycle studies showed that the effects of LY294002 and proteasome inhibitor on the abundance of $\mathrm{p} 300$ protein were not due to the toxicity of these reagents (Fig. 2D and E). We concluded that the LY294002-stimulated p300 degradation may be mediated through the $26 \mathrm{~S}$ proteasome.

\section{PI3K activity is required for maintaining the stability and function of p300.}

To evaluate whether the negative effect of LY294002 on the steady-state level of p300 protein could also be attained through repression of p300 gene expression, we performed quantitative RT-PCR on p300 transcripts after the LY294002 treatment. As shown in Fig. 3A, treatment of HeLa cells with LY294002 or MG132 did not affect the relative $\mathrm{p} 300$ gene expression, confirming that the down-regulation of $\mathrm{p} 300$ protein by 
LY2940002 was largely mediated through selective p300 degradation. To further verify the specificity of LY294002 in the selective p300 degradation, we examined the metabolic stability of p300 in the presence or the absence of LY294002 using pulse-chase protocol. As shown in Fig. 3B, the stability of p300 protein was significantly reduced in LY294002-treated cells compared to that in untreated cells. Together, these data suggest that the PI3K pathway plays a role in maintaining the critical level of p300 protein and may have an impact on $\mathrm{p} 300$ function.

Next, we wished to assess whether LY294002 also has a negative effect on the transcriptional activity of $\mathrm{p} 300$. The function of the coactivator $\mathrm{p} 300$ is essential for transcriptional activation mediated by retinoic acid receptor (RAR) $[56,57]$ and fibroblasts derived from p300 knock-out embryos were deficient in RAR-dependent transcription [2]. We thus assessed the impact of LY294002 on RAR signaling using a retinoic acid-responsive reporter ( $\beta$ RE3-Luc), a synthetic RAR-specific ligand, TTNPB, and a $\beta$-galactosidase vector as an internal control. As shown in Figure 3C, transfection of the cells with the $\beta$ RE3-Luc reporter alone results in about 70 -fold increase of TTNPB-induced transcription relative to the untreated control. However, in the presence of LY294002, the RAR-mediated transcription was reduced to about 30-fold. In addition, Western analysis showed that the level of RAR protein was not affected by treatment of the cells with LY294002 (Fig. 3D). This suggests that the inhibitory effects of LY294002 on the RAR-mediated transcription are achieved through the selective p300 degradation, as LY294002 induces p300 degradation (Fig. 2A and 3B) and the RARmediated transcription depends on the activity of p300 [2]. 


\section{Akt interacts with the transcriptional coactivator $\mathbf{p} 300$.}

We also wished to determine the molecular mechanisms by which the PI3K pathway regulates the metabolic stability of $\mathrm{p} 300$. One major downstream target of PI3K is Akt [58] and protein sequence analysis revealed that p300 contains one putative Akt phosphorylation site (RXRXXS, 1829-1834). Both the synthetic peptide and purified p300 fragment harboring this optimal motif have been shown to be targets for Akt phosphorylation $[33,34]$. We therefore focused on whether Akt is the downstream molecule that mediates the effect of the PI3K pathway on p300 activity.

First, we assessed the phosphorylation of Akt at Ser-473 upon cycloheximide treatment by using a specific phosphor-Akt antibody (Ser473) in the Western analysis, since Akt is activated by phosphorylation at the Ser-473 [59]. As shown in Fig. 4A, the phosphorylation of Akt at the Ser-473 was augmented significantly following the administration of cyclohxiemide to the culture, confirming that the level of activated Akt in the cells was indeed enhanced by the cycloheximide treatment.

Next, we examined the association of Akt with p300 in a coimmunoprecipitation protocol. Using immobilized Akt monoclonal antibody to precipitate the endogenous Akt from cell lysate and p300 antibody for Western blot analysis, we detected p300 protein in the Akt antibody precipitation but not in the negative control (Fig. 4B). This suggests that the endogenous p300 protein is able to interact with the endogenous Akt, underlying the physiological relevance of the interaction between p300 and Akt. We also mapped the region of p300 that interacts with Akt using a GST pull-down assay. Different GSTp300 fusion proteins spanning the full-length region of p300 [43] were used in the pulldown experiment to examine their ability to associate with constitutively active Akt [45] 
transiently expressed in HeLa cells. Western analysis of the bound protein using a specific Akt antibody demonstrated that p300 is able to interact with the constitutively active Akt and the region that does so was mapped mainly to the p300 fragment corresponding to amino acid 1459-1892 containing the Akt phosphorylation site (Fig. $4 C)$.

\section{Akt activity is required to maintain the protein stability of endogenous p300.}

To assess whether the Akt activity is essential for maintaining the protein stability of endogenous p300, two variants of ovarian cancer cell line A2780S were employed. One is a stable cell line expressing HA-tagged constitutively active Akt2, and the other is a control stable line containing the empty vector. The activity of the constitutively active Akt in the stable cells was verified by Western blot and in vitro kinase analysis [60]. Quantitative RT-PCR analysis of p300 mRNA showed that the relative p300 gene expression was not affected by LY294002 treatment in these two cell lines (Fig. 5A). A cell cycle study demonstrated that the addition of LY294002 to the control cells resulted in an elevated subG1 peak (18.77\%), while LY294002 had a much less pronounced effect on the subG1 peak $(8.93 \%)$ of the stable cells stably expressing the constitutively active Akt (Fig. 5B), confirming that the activity of Akt in the stable cells expressing constitutively active Akt does not depend on PI3K.

Most importantly, the LY294002 treatment caused a similar reduction of endogenous p300 protein in the control cells as in the HeLa cells, but it did not decrease the steady-state level of the coactivator in the stable cells expressing constitutive active Akt (Fig. 5C). Immunofluorescence microscopy analysis illustrated that p300 was 
localized in the nucleus in both cell lines with or without the LY294002 treatment, while Akt was detected in both the nuclear and cytoplasmic compartments of the cells (Fig. 5D). In agreement with the results of Western analysis, the level of $\mathrm{p} 300$ stain following LY294002 addition was decreased in the control cells while it was not obviously changed in stable cells expressing the constitutively active Akt (Fig. 5D). Additionally, the cycloheximide treatment reduced the phosphorylation of Akt in the stable cells expressing the constitutively active Akt, and the abundance of $\mathrm{p} 300$ protein was decreased consequently (Fig. 5E). Taken together, these data suggest that Akt activity is essential for sustaining the metabolic stability of endogenous $\mathrm{p} 300$ protein. 


\section{Discussion}

The major conclusion of this work is that the activity of p300 is regulated by the pro-survival kinase Akt. We show that p300 interacts with Akt and the Akt activity is essential for maintaining the critical steady-state level and the transcriptional activity of p300 (Fig. 4 and 5), underlying the intricacy and complexity of the cell signaling pathways in the control of cell survival.

Only recently has Akt been recognized as an important regulator of mammalian cell proliferation and survival. There is strong evidence to support the role of Akt in the anti-apoptotic pathway to promote cell survival [23]. Akt can also influence the prosurvival pathway through an indirect effect on the pro-survival transcription factor NFאB, which, however, would affect only a specific set of genes that is under the control of NFkB [42]. Our results demonstrate that the transcriptional integrator p300 interacts with Akt and the Akt activity is necessary to maintain the steady-state level of p300 protein (Fig. 4 and 5). Thus, a transcriptional coactivator, or an integrator, is added to the repertoire of Akt targets, which implies not only a much broader role for Akt in control of gene expression, but also a role for Akt in chromatin remodeling as p300 is a histone acetyltransferase.

Activation of gene expression requires the coordinated action of sequencespecific transcription factors and coactivators to recruit the transcription machinery at target promoters [61]. The function of p300 is required by many transcription factors including some pro-survival or pro-apoptotic factors, such as NFkB, p53 and c-Jun [3]. Direct competition for the limited amount of p300 at the overlapping binding site of p300 has been shown to be the molecular mechanism to synchronize the expression or 
repression of multiple genes [62]. However, the conventional wisdom that p300 is recruited by the transcription factors to the promoter in order to remodel chromatin structure and to facilitate gene expression presents an active role for p300 as a transcriptional activator, but a passive role as an integrator, as a consequence of competition amongst the different transcription factors.

The association of Akt activity with p300 function rightfully places the integrator p300 at the upstream of the signal-modulated survival pathway and shed new light on the intricacy of cell survival and apoptosis. One good example is the involvement of both Akt and p300 in the regulation of transcriptional activity of the transcription factors $\mathrm{NF \kappa B}$ and $\mathrm{p} 53$. Phosphorylation of Mdm2 by Akt stimulates its nuclear translocation, resulting in the destabilization of $\mathrm{p} 53$, a pro-apoptotic factor whose function requires p300 [38, 39]. On the other hand, Akt phosphorylation indirectly enhances the activity of $\mathrm{NF} \kappa \mathrm{B}$, a pro-survival factor that also requires the function of $\mathrm{p} 300[3,41,42]$. Here we showed that the Akt activity is essential for maintaining the critical concentration of p300 protein (Fig. 5). Thus, other than at the level of the transcription factors, Akt can also promote cell survival and stifle apoptosis at the level of the transcriptional coactivator, or integrator.

The total gene dosage of p300 is critical for development and cell proliferation [2] and the role of p300 in cell survival is connected with various transcription factors that are either pro-survival or pro-apoptotic [3]. Our study reveals that the PI3K signaling pathway modulates p300 activity and suggests a role for p300 as a transcriptional integrator in cell survival. 


\section{Acknowledgements}

We thank Michael Fraser and Gérard Benoit for expertise and Drs. J. Cheng, V.

Giguere, Y. Gotoh, M.O. Hottiger, and T. Perlmann for cell lines and DNA plasmids.

We also thank The Cancer Research Society Inc., Canadian Institutes of Health Research (CIHR) and National Cancer Institute of Canada for support of operating grants. During the course of this study, Q.L. is supported by scholarships from the CIHR. 


\section{References}

1. Janknecht R. and Hunter T. (1996) Versatile molecular glue. Transcriptional control. Curr Biol 6: 951-954.

2. Yao T.P., Oh S.P., Fuchs M., Zhou N.D., Ch'ng L.E., Newsome D., Bronson R.T., Li E., Livingston D.M. and Eckner R. (1998) Gene dosage-dependent embryonic development and proliferation defects in mice lacking the transcriptional integrator p300. Cell 93: 361-372

3. Goodman R.H. and Smolik S. (2000) CBP/p300 in cell growth, transformation, and development. Genes Dev 14: 1553-1577

4. Li Q., Herrler M., Landsberger N., Kaludov N., Ogryzko V.V., Nakatani Y. and Wolffe A.P. (1998) Xenopus NF-Y pre-sets chromatin to potentiate p300 and acetylation- responsive transcription from the Xenopus hsp70 promoter in vivo. EMBO J 17: 6300-6315

5. Li Q., Imhof A., Collingwood T.N., Urnov F.D. and Wolffe A.P. (1999) p300 stimulates transcription instigated by ligand-bound thyroid hormone receptor at a step subsequent to chromatin disruption. EMBO J 18: 5634-5652

6. Ait-Si-Ali S., Ramirez S., Barre F.X., Dkhissi F., Magnaghi-Jaulin L., Girault J.A., Robin P., Knibiehler M., Pritchard L.L., Ducommun B., Trouche D. and Harel-Bellan A. (1998) Histone acetyltransferase activity of CBP is controlled by cycle- dependent kinases and oncoprotein E1A. Nature 396: 184-186

7. See R.H., Calvo D., Shi Y., Kawa H., Luke M.P. and Yuan Z. (2001) Stimulation of p300-mediated transcription by the kinase MEKK1. J Biol Chem 276: 1631016317. 
8. Yuan L.W. and Gambee J.E. (2000) Phosphorylation of p300 at serine 89 by protein kinase C. J Biol Chem 275: 40946-40951.

9. Li Q., Su A., Chen J., Lefebvre Y.A. and Hache R.J. (2002) Attenuation of Glucocorticoid Signaling through Targeted Degradation of p300 via the $26 \mathrm{~S}$ Proteasome Pathway. Mol Endocrinol 16: 2819-2827.

10. Avantaggiati M.L., Carbone M., Graessmann A., Nakatani Y., Howard B. and Levine A.S. (1996) The SV40 large T antigen and adenovirus E1a oncoproteins interact with distinct isoforms of the transcriptional co-activator, p300. EMBO J 15: $2236-2248$.

11. Schwartz C., Beck K., Mink S., Schmolke M., Budde B., Wenning D. and Klempnauer K.H. (2003) Recruitment of p300 by C/EBPbeta triggers phosphorylation of p300 and modulates coactivator activity. EMBO J 22: 882892.

12. Girdwood D., Bumpass D., Vaughan O.A., Thain A., Anderson L.A., Snowden A.W., Garcia-Wilson E., Perkins N.D. and Hay R.T. (2003) p300 Transcriptional Repression Is Mediated by SUMO Modification. Mol Cell 11: 1043-1054.

13. Kiernan R.E., Vanhulle C., Schiltz L., Adam E., Xiao H., Maudoux F., Calomme C., Burny A., Nakatani Y., Jeang K.T., Benkirane M. and Van Lint C. (1999) HIV-1 tat transcriptional activity is regulated by acetylation. EMBO J 18: 61066118

14. Yang J., Kawai Y., Hanson R.W. and Arinze I.J. (2001) Sodium butyrate induces transcription from the $\mathrm{G}$ alpha(i2) gene promoter through multiple $\mathrm{Sp} 1$ sites in the 
promoter and by activating the MEK-ERK signal transduction pathway. J Biol Chem 276: 25742-25752.

15. Tichonicky L., Santana-Calderon M.A., Defer N., Giesen E.M., Beck G. and Kruh J. (1981) Selective inhibition by sodium butyrate of glucocorticoid-induced tyrosine aminotransferase synthesis in hepatoma tissue-cultured cells. Eur J Biochem 120: 427-433.

16. Bartsch J., Truss M., Bode J. and Beato M. (1996) Moderate increase in histone acetylation activates the mouse mammary tumor virus promoter and remodels its nucleosome structure. Proc Natl Acad Sci USA 93: 10741-10746

17. Bresnick E.H., John S., Berard D.S., LeFebvre P. and Hager G.L. (1990) Glucocorticoid receptor-dependent disruption of a specific nucleosome on the mouse mammary tumor virus promoter is prevented by sodium butyrate. Proc Natl Acad Sci USA 87: 3977-3981

18. Lambert J.R. and Nordeen S.K. (1998) Steroid-selective initiation of chromatin remodeling and transcriptional activation of the mouse mammary tumor virus promoter is controlled by the site of promoter integration. J Biol Chem 273: $32708-32714$.

19. Kruh J. (1982) Effects of sodium butyrate, a new pharmacological agent, on cells in culture. Mol Cell Biochem 42: 65-82.

20. Lee E., Furukubo T., Miyabe T., Yamauchi A. and Kariya K. (1996) Involvement of histone hyperacetylation in triggering DNA fragmentation of rat thymocytes undergoing apoptosis. FEBS Lett 395: 183-187. 
21. McBain J.A., Eastman A., Nobel C.S. and Mueller G.C. (1997) Apoptotic death in adenocarcinoma cell lines induced by butyrate and other histone deacetylase inhibitors. Biochem Pharmacol 53: 1357-1368.

22. Medina V., Edmonds B., Young G.P., James R., Appleton S. and Zalewski P.D. (1997) Induction of caspase-3 protease activity and apoptosis by butyrate and trichostatin A (inhibitors of histone deacetylase): dependence on protein synthesis and synergy with a mitochondrial/cytochrome c- dependent pathway. Cancer Res 57: 3697-3707.

23. Vivanco I. and Sawyers C.L. (2002) The phosphatidylinositol 3-Kinase AKT pathway in human cancer. Nat Rev Cancer 2: 489-501.

24. Datta S.R., Brunet A. and Greenberg M.E. (1999) Cellular survival: a play in three Akts. Genes Dev 13: 2905-2927.

25. Brazil D.P. and Hemmings B.A. (2001) Ten years of protein kinase B signalling: a hard Akt to follow. Trends Biochem Sci 26: 657-664.

26. Dudek H., Datta S.R., Franke T.F., Birnbaum M.J., Yao R., Cooper G.M., Segal R.A., Kaplan D.R. and Greenberg M.E. (1997) Regulation of neuronal survival by the serine-threonine protein kinase Akt. Science 275: 661-665.

27. Khwaja A., Rodriguez-Viciana P., Wennstrom S., Warne P.H. and Downward J. (1997) Matrix adhesion and Ras transformation both activate a phosphoinositide 3-OH kinase and protein kinase B/Akt cellular survival pathway. EMBO J 16: 2783-2793. 
28. Kennedy S.G., Wagner A.J., Conzen S.D., Jordan J., Bellacosa A., Tsichlis P.N. and Hay N. (1997) The PI 3-kinase/Akt signaling pathway delivers an antiapoptotic signal. Genes Dev 11: 701-713.

29. Kulik G., Klippel A. and Weber M.J. (1997) Antiapoptotic signalling by the insulin-like growth factor I receptor, phosphatidylinositol 3-kinase, and Akt. Mol Cell Biol 17: 1595-1606.

30. Kennedy S.G., Kandel E.S., Cross T.K. and Hay N. (1999) Akt/Protein kinase B inhibits cell death by preventing the release of cytochrome $\mathrm{c}$ from mitochondria. Mol Cell Biol 19: 5800-5810.

31. Alessi D.R., Caudwell F.B., Andjelkovic M., Hemmings B.A. and Cohen P. (1996) Molecular basis for the substrate specificity of protein kinase B; comparison with MAPKAP kinase-1 and p70 S6 kinase. FEBS Lett 399: 333-338.

32. Obata T., Yaffe M.B., Leparc G.G., Piro E.T., Maegawa H., Kashiwagi A., Kikkawa R. and Cantley L.C. (2000) Peptide and protein library screening defines optimal substrate motifs for AKT/PKB. J Biol Chem 275: 36108-36115.

33. Guo S., Cichy S.B., He X., Yang Q., Ragland M., Ghosh A.K., Johnson P.F. and Unterman T.G. (2001) Insulin suppresses transactivation by CAAT/enhancerbinding proteins beta (C/EBPbeta). Signaling to $\mathrm{p} 300 / \mathrm{CREB}-$ binding protein by protein kinase $\mathrm{B}$ disrupts interaction with the major activation domain of C/EBPbeta. J Biol Chem 276: 8516-8523

34. Mayo M.W., Denlinger C.E., Broad R.M., Yeung F., Reilly E.T., Shi Y. and Jones D.R. (2003) Ineffectiveness of Histone Deacetylase Inhibitors to Induce 
Apoptosis Involves the Transcriptional Activation of NF- $\{$ kappa $\}$ B through the Akt Pathway. J Biol Chem 278: 18980-18989.

35. Datta S.R., Dudek H., Tao X., Masters S., Fu H., Gotoh Y. and Greenberg M.E. (1997) Akt phosphorylation of BAD couples survival signals to the cell- intrinsic death machinery. Cell 91: 231-241.

36. Cardone M.H., Roy N., Stennicke H.R., Salvesen G.S., Franke T.F., Stanbridge E., Frisch S. and Reed J.C. (1998) Regulation of cell death protease caspase-9 by phosphorylation. Science 282: 1318-1321.

37. Brunet A., Bonni A., Zigmond M.J., Lin M.Z., Juo P., Hu L.S., Anderson M.J., Arden K.C., Blenis J. and Greenberg M.E. (1999) Akt promotes cell survival by phosphorylating and inhibiting a Forkhead transcription factor. Cell 96: 857-868.

38. Mayo L.D. and Donner D.B. (2001) A phosphatidylinositol 3-kinase/Akt pathway promotes translocation of Mdm2 from the cytoplasm to the nucleus. Proc Natl Acad Sci U S A 98: 11598-11603.

39. Zhou B.P., Liao Y., Xia W., Zou Y., Spohn B. and Hung M.C. (2001) HER-2/neu induces p53 ubiquitination via Akt-mediated MDM2 phosphorylation. Nat Cell Biol 3: 973-982.

40. Ozes O.N., Mayo L.D., Gustin J.A., Pfeffer S.R., Pfeffer L.M. and Donner D.B. (1999) NF-kappaB activation by tumour necrosis factor requires the Akt serinethreonine kinase. Nature 401: 82-85.

41. Kane L.P., Shapiro V.S., Stokoe D. and Weiss A. (1999) Induction of NF-kappaB by the Akt/PKB kinase. Curr Biol 9: 601-604. 
42. Romashkova J.A. and Makarov S.S. (1999) NF-kappaB is a target of AKT in antiapoptotic PDGF signalling. Nature 401: 86-90.

43. Hasan S., Hassa P.O., Imhof R. and Hottiger M.O. (2001) Transcription coactivator $\mathrm{p} 300$ binds PCNA and may have a role in DNA repair synthesis. Nature 410: 387-391.

44. Perlmann T. and Jansson L. (1995) A novel pathway for vitamin A signaling mediated by RXR heterodimerization with NGFI-B and NURR1. Genes Dev 9: 769-782.

45. Ogawara Y., Kishishita S., Obata T., Isazawa Y., Suzuki T., Tanaka K., Masuyama N. and Gotoh Y. (2002) Akt enhances Mdm2-mediated ubiquitination and degradation of p53. J Biol Chem 277: 21843-21850.

46. Buckwalter C.A., Lin A.H., Tanizawa A., Pommier Y.G., Cheng Y.C. and Kaufmann S.H. (1996) RNA synthesis inhibitors alter the subnuclear distribution of DNA topoisomerase I. Cancer Res 56: 1674-1681.

47. Candido E.P., Reeves R. and Davie J.R. (1978) Sodium butyrate inhibits histone deacetylation in cultured cells. Cell 14: $105-113$

48. Wolffe A.P., Wong J., Li Q., Levi B.Z. and Shi Y.B. (1997) Three steps in the regulation of transcription by the thyroid hormone receptor: establishment of a repressive chromatin structure, disruption of chromatin and transcriptional activation. Biochem Soc Trans 25: 612-615

49. Obrig T.G., Culp W.J., McKeehan W.L. and Hardesty B. (1971) The mechanism by which cycloheximide and related glutarimide antibiotics inhibit peptide synthesis on reticulocyte ribosomes. J Biol Chem 246: 174-181. 
50. Yaciuk P. and Moran E. (1991) Analysis with specific polyclonal antiserum indicates that the E1A- associated $300-\mathrm{kDa}$ product is a stable nuclear phosphoprotein that undergoes cell cycle phase-specific modification. Mol Cell Biol 11: 5389-5397.

51. Grollman A.P. (1967) Inhibitors of protein biosynthesis. II. Mode of action of anisomycin. J Biol Chem 242: 3226-3233.

52. Hemi R., Paz K., Wertheim N., Karasik A., Zick Y. and Kanety H. (2002) Transactivation of ErbB2 and ErbB3 by tumor necrosis factor-alpha and anisomycin leads to impaired insulin signaling through serine/threonine phosphorylation of IRS proteins. J Biol Chem 277: 8961-8969.

53. Vlahos C.J., Matter W.F., Hui K.Y. and Brown R.F. (1994) A specific inhibitor of phosphatidylinositol 3-kinase, 2-(4- morpholinyl)-8-phenyl-4H-1-benzopyran-4one (LY294002). J Biol Chem 269: 5241-5248.

54. Okada T., Kawano Y., Sakakibara T., Hazeki O. and Ui M. (1994) Essential role of phosphatidylinositol 3-kinase in insulin-induced glucose transport and antilipolysis in rat adipocytes. Studies with a selective inhibitor wortmannin. J Biol Chem 269: 3568-3573.

55. Lee D.H. and Goldberg A.L. (1998) Proteasome inhibitors: valuable new tools for cell biologists. Trends Cell Biol 8: 397-403

56. Chakravarti D., LaMorte V.J., Nelson M.C., Nakajima T., Schulman I.G., Juguilon H., Montminy M. and Evans R.M. (1996) Role of CBP/P300 in nuclear receptor signalling. Nature 383: 99-103 
57. Kawasaki H., Eckner R., Yao T.P., Taira K., Chiu R., Livingston D.M. and Yokoyama K.K. (1998) Distinct roles of the co-activators p300 and CBP in retinoic-acid- induced F9-cell differentiation. Nature 393: 284-289.

58. Franke T.F., Kaplan D.R., Cantley L.C. and Toker A. (1997) Direct regulation of the Akt proto-oncogene product by phosphatidylinositol-3,4-bisphosphate.

Science 275: 665-668.

59. Alessi D.R., Andjelkovic M., Caudwell B., Cron P., Morrice N., Cohen P. and Hemmings B.A. (1996) Mechanism of activation of protein kinase B by insulin and IGF-1. EMBO J 15: 6541-6551

60. Yuan Z.Q., Feldman R.I., Sussman G.E., Coppola D., Nicosia S.V. and Cheng J.Q. (2003) AKT2 inhibition of cisplatin-induced JNK/p38 and Bax activation by phosphorylation of ASK1: Implication of AKT2 in chemoresistance. J Biol Chem 278: $23432-23440$

61. Greenblatt J. (1997) RNA polymerase II holoenzyme and transcriptional regulation. Curr Opin Cell Biol 9: 310-319.

62. Kamei Y., Xu L., Heinzel T., Torchia J., Kurokawa R., Gloss B., Lin S.C., Heyman R.A., Rose D.W., Glass C.K. and Rosenfeld M.G. (1996) A CBP integrator complex mediates transcriptional activation and AP-1 inhibition by nuclear receptors. Cell 85: 403-414 


\section{Figure Legends}

Fig. 1. Effects of cycloheximide on the abundance of endogenous p300 protein. (A) Equal amount of whole-cell extracts from HeLa cells $(50 \mu \mathrm{g})$ was used for Western blot analysis to assess the levels of endogenous p300 protein following the addition of sodium butyrate $(\mathrm{NaB}, 5 \mathrm{mM})$ and/or cycloheximide $(\mathrm{CHX}, 40 \mu \mathrm{g} / \mathrm{ml})$. The duration of treatments is indicated in hours. The blots were then stripped and reprobed for protein loading with SRC antibody. Result shown is representative of four independent experiments. (B) Same experimental set up as in (A) except that blot was sequentially analyzed for p300 and cyclin E. (C) The HeLa cells were pretreated with or without cycloheximide for 22 hours and labeled with ${ }^{35}$ S-methionine in the same pretreatment condition for 2 hours in triplicate. The rate of protein synthesis was calculated as incorporated radioactivity per microgram of protein. Error bars represent the standard deviations of the triplicates. (D) After metabolic labeling with ${ }^{35} \mathrm{~S}$-methionine and various hours of chase, the endogenous p300 protein was immunopurified, separated by SDS-PAGE and quantified by PhosphorImager. The experiment was repeated three times in duplicate. The apparent half-life of endogenous p300 protein is $11.3 \pm 1.5$ hours.

Fig. 2. LY294002 induces proteasome-mediated p300 degradation. (A) Equal amounts $(50 \mu \mathrm{g})$ of whole-cell extracts from HeLa cells were used for Western blot analysis of endogenous p300 protein following 20 hours of treatments with LY294002 (LY, $20 \mu \mathrm{M})$ with or without cycloheximide $(40 \mu \mathrm{g} / \mathrm{ml}), \operatorname{MG} 132(5 \mu \mathrm{M})$. The blot was then stripped and reprobed with p53 antibody. (B) Western blot analysis was used to assess the levels 
of endogenous p300 protein following the 20 hours treatment with LY294002 and/or lactacystin (Lac, $10 \mu \mathrm{M})$ and MG132. The blots were then stripped and reprobed with p53 antibody. (C) Same experimental set up as in (B) except that MG115 (25 $\mu \mathrm{M})$ and ALLN $(50 \mu \mathrm{M})$ were used. (D) Following time course treatments with LY294002 and MG132, HeLa cells were analyzed using immunofluorescence microscopy to reveal the cellular distribution of endogenous $\mathrm{p} 300$. Shown is representative of four independent experiments. (E) Flow cytometry analysis of DNA content (propidium iodide uptake) of HeLa cells following different periods of LY194002 and MG132 treatments. Shown is representative of three independent experiments.

Fig. 3. Effects of PI3K on the protein stability of p300. (A) HeLa cells were treated with LY294002 (LY, $20 \mu \mathrm{M})$ and MG132 (MG, $5 \mu \mathrm{M})$ for 20 hours. Total RNA was isolated and quantitative RT-PCR was conducted to determine p300 mRNA levels. Results show fold variations of p300 mRNA levels compared to untreated cells. Standard errors of mean are shown. The experiment was repeated at least 5 times. (B) Cells were treated with LY294002 for 7 hours and subjected to the pulse-chase protocol ( 3 and 6 hours) in the presence of LY294002 as compared to the control cells without the LY294002 treatment through out the culture and pulse-chase protocol. Then, the endogenous p300 protein was immunopurified, separated by SDS-PAGE and quantified by PhosphorImager. (C) HeLa cells were transfected with RAR reporter $(0.3 \mu \mathrm{g})$ and RSV$\beta$-Gal $(0.3 \mu \mathrm{g})$. Following 24 hours of induction with TTNPB $(1 \mu \mathrm{M})$ in the presence or absence of LY294002, the cells were harvested for luciferase assay. The luciferase activity was normalized to $\beta$-galactosidase activity and expressed as fold induction 
relative to untreated controls. The experiment was repeated three times in triplicate. Error bars represent the standard deviations of the triplicates. (D) Equal amounts (50 $\mu \mathrm{g})$ of whole-cell extracts from HeLa cells were used for Western blot analysis of p300 following 12 or 20 hours of treatment with LY294002 (lanes 2 and 3, respectively). The blot was then stripped and reprobed with antibody specific for RAR receptor.

Fig. 4. Akt interacts with p300. (A) Equal amounts of whole-cell extracts from HeLa cells were used for Western blot analysis of endogenous p300 protein and phosphorylation of Akt at Ser-473 (p*Akt) following 20 hours of treatments with cycloheximide (CHX, $40 \mu \mathrm{g} / \mathrm{ml})$. (B) A cell lysate of A2780S cells was immunoprecipitated with Akt antibody and antibody specific for p300 was used to detect the p300 protein coimmunoprecipitated with the Akt antibody (lanes 2 and 3). The blot was then striped and reprobed with Akt antibody. Protein A beads without the Akt antibody were used as negative control (lane 1) in the procedure. (C) About $5 \mu \mathrm{g}$ of GST-p300 fusion proteins (p300-1: amino acid 1-672; p300-2: 672-1193; p300-3: 10691459; p300-4: 1459-1892; p300-5: 1893-2414) and $500 \mu \mathrm{g}$ of cell lysate from HeLa cells expressing constitutively active Akt was used in each pull down assay. The blot was probed with antibody specific to Akt and GST. 10\% of the cell lysate used in the pull down assay was included as an input control (lanes 6). Shown also is the schematic presentation of different truncated forms of GST-p300 fusion protein used in the pulldown assay. 
Fig. 5. Akt activity is essential for maintaining the steady-state level of endogenous p300 protein. (A) Ovarian carcinoma A2780S cells with a stably integrated plasmid for constitutively active Akt (A-caAkt) or the empty vector (A-vector) were treated with LY294002 (LY, $20 \mu \mathrm{M}$ ) for 20 hours. Total RNA was isolated and quantitative RT-PCR was conducted to determine p300 mRNA levels. Results show fold variations of p300 mRNA levels compared to untreated cells. Standard errors of mean are shown. The experiment was repeated 5 times. (B) Flow cytometry analysis of DNA content (propidium iodide uptake) of the two cell lines with or without the LY194002 treatment. The percentage of cells in subG1 peak is indicated in the corresponding profiles. Shown is representative of four independent experiments. (C) Equal amounts (50 $\mu \mathrm{g})$ of wholecell extracts from the A-caAkt and control cells were used for Western blot analysis with antibodies against p300 and SRC after treatment with LY294002 and/or MG132 (5 $\mu \mathrm{M})$ for 20 hours. Shown is representative of three independent experiments. (D) Following treatment with LY294002, the A-caAkt and control cells were analyzed using immunofluorescence microscopy to reveal the cellular distribution of endogenous p300 and Akt. Shown is representative of three independent experiments. (E) Phospho-Akt antibody (anti-p*Akt) was used for Western blot analysis of the A-caAkt cells following the treatment with cycloheximide (CHX, $40 \mu \mathrm{g} / \mathrm{ml})$. 

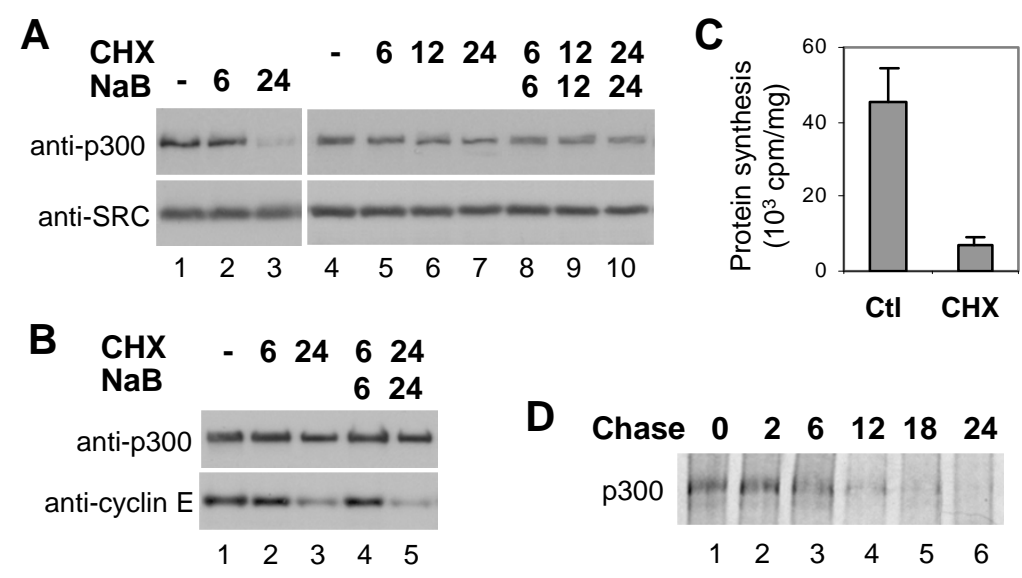

Figure 1

Chen et al. 

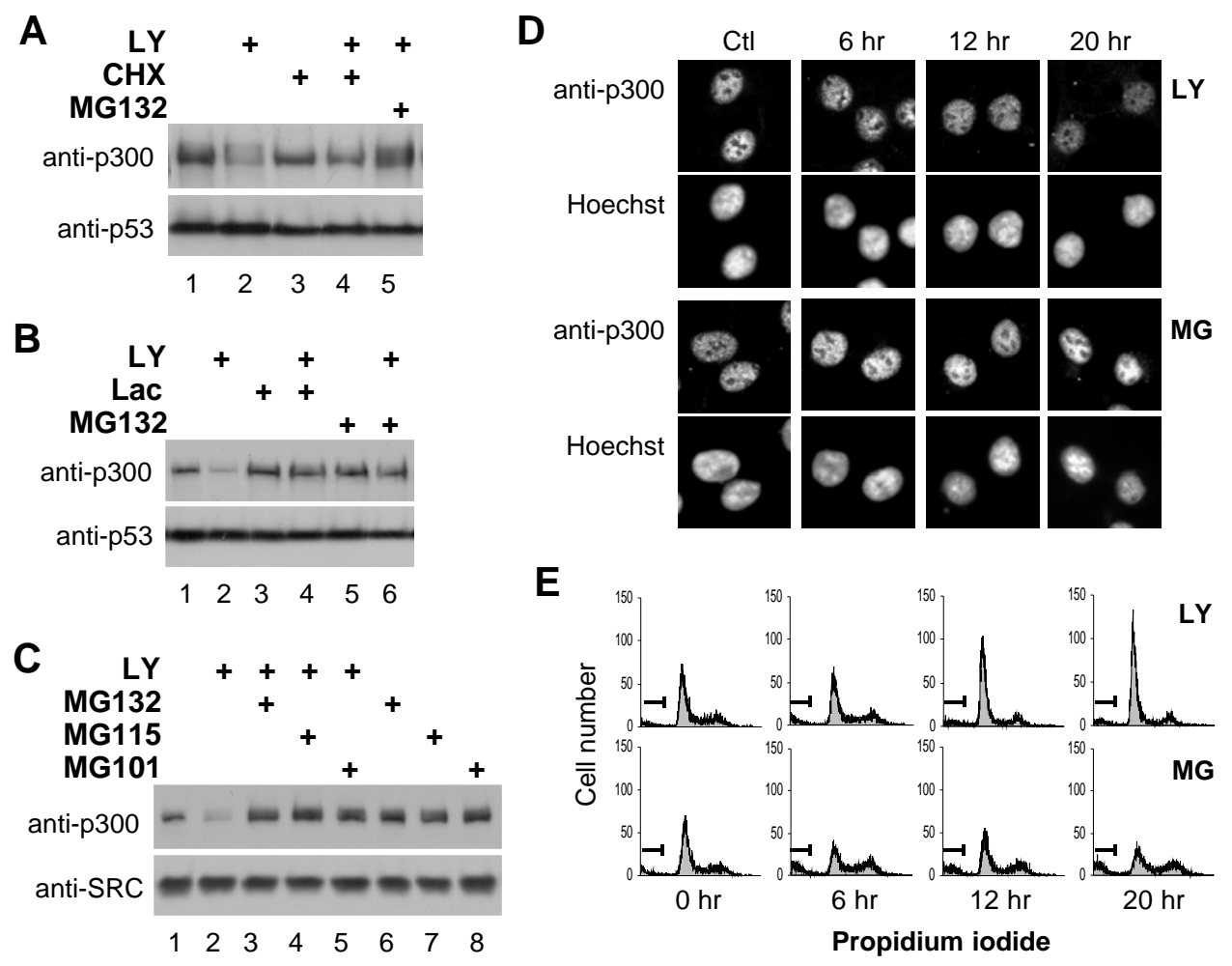

Figure 2

Chen et al. 

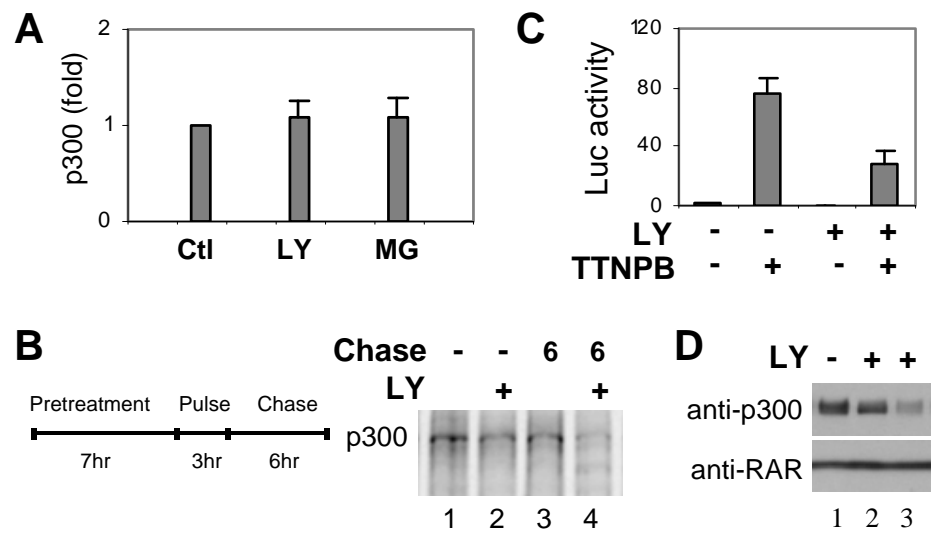

Figure 3

Chen et al. 

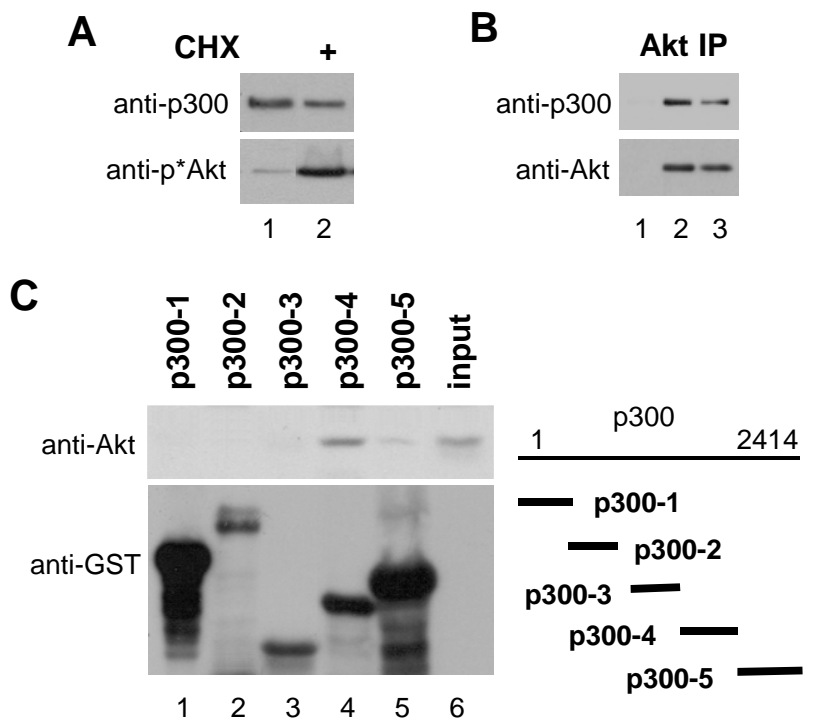

Figure 4

Chen et al. 

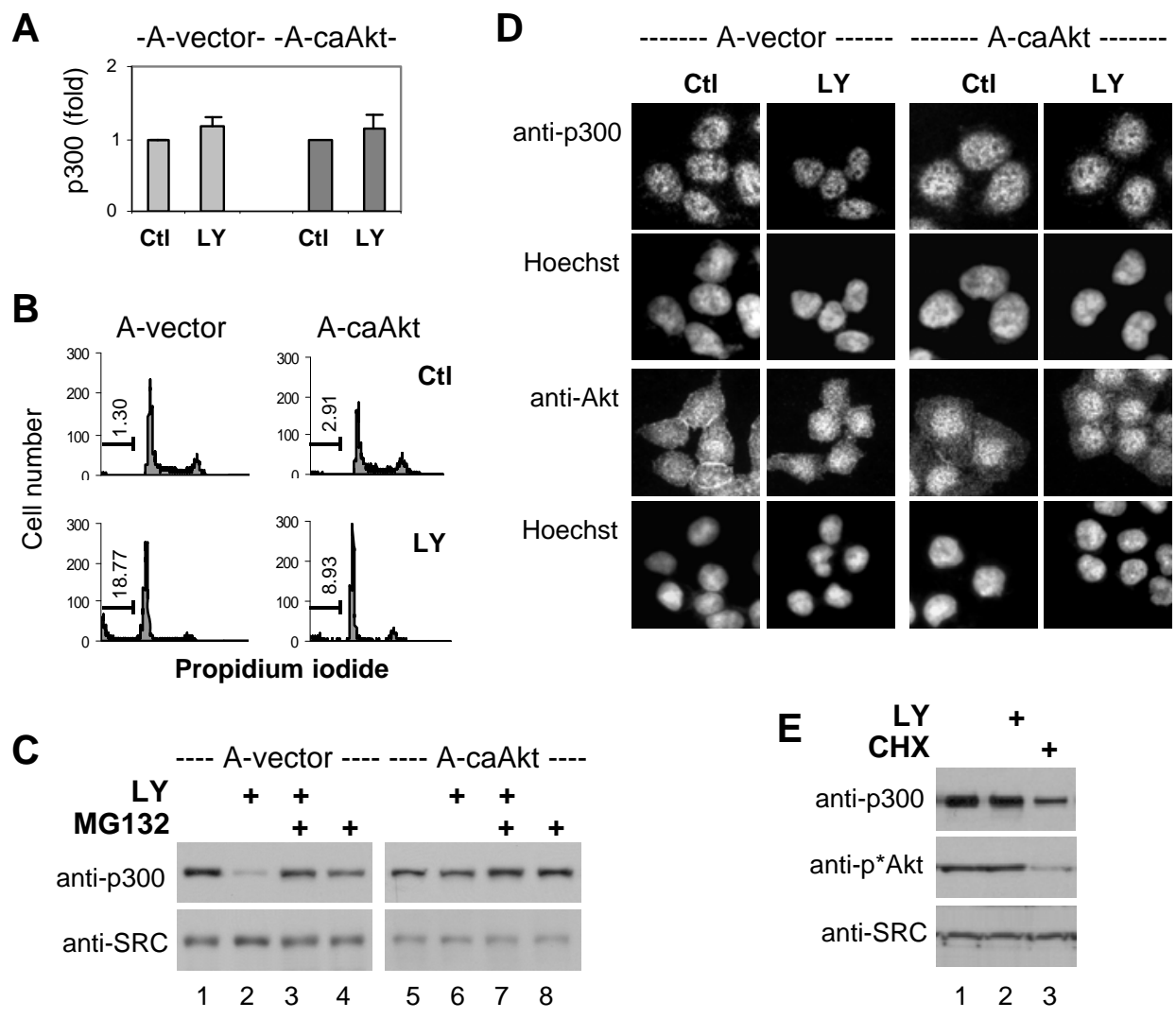

Figure 5

Chen et al. 